GU J Sci, Part C, 5(4): 1-11 (2017)

Gazi Üniversitesi
Fen Bilimleri Dergisi
PART C: TASARIM VE TEKNOLOJI
dergipark.gov.tr/http-gujsc-gazi-edu-tr

\title{
Uçak Bakım Tahsis Sürelerinin Belirlenmesine Yönelik Yeni Bir Method Geliştirilmesi
}

\author{
Davut YILMAZ ${ }^{1 *}$, İbrahim ÖZKOL ${ }^{2}$ \\ ${ }^{I}$ Istanbul Teknik Üniversitesi, Uçak ve Uzay Bilimleri Fakültesi, Uçak Mühendisliği Bölümü, Maslak/ISTANBUL \\ ${ }^{2}$ Istanbul Teknik Üniversitesi, Uçak ve Uzay Bilimleri Fakültesi, Uçak Mühendisliği Bölümü, Maslak/ISTANBUL
}

\begin{abstract}
Öz
Makale Bilgisi

Başvuru: 20/02/2017

Düzeltme: 27/07/2017

Kabul: 27/09/2017

Anahtar Kelimeler

Uçak bakımı

YSA

Yapay zeka

Keywords

Bir uçağın tasarımı aşamasında en önemli konulardan biri, komponentlerin bakım tahsis sürelerinin belirlenmesidir. Geleneksel bakım tahsis yöntemleri, genellikle tecrübi bilgiye dayalı olup, tasarım ofisinin kontrolü dışındadır. Bu çalışmada, uçak bakım tahsis sürelerinin belirlenmesi için bir yöntem geliştirilerek, tecrübi yönteme bir alternatif oluşturulması hedeflenmiştir. $\mathrm{Bu}$ amaçla, iki aşamalı bir çalışma yapılmış olup, ilk aşamada var olan bir çalışma, farklı bir yöntemle ele alınarak geliştirilmiş ve uçak sistemleri ya da komponentleri ile bakım kartlarının süreleri arasında bir korelasyon oluşturulmuştur. Çalıșmanın ikinci aşamasında, Bakım Yürütme Grubu'nun belirlediği ve günümüzde artık standart kabul edilen temel bakım tasklarının parametreleri detaylı olarak ele alınmış, bu amaçla 1000'den fazla bakım uygulaması incelenerek kantitatif analizler gerçekleştirilmiş ve toplamda 6 adet ağırlık katsayısı elde edilmiştir. Çalışmanın devamında ise ilk bölümde elde edilen fonksiyonla yeni modüller elde edilmiş ve uçaktaki tüm sistemler ya da komponentler için uygulanabilir bir seviyeye getirilmiştir. Son bölümde ise elde edilen ağılık katsayıları arasındaki ilişki ileri beslemeli geri yayılımlı yapay sinir ağları ile analiz edilerek, uçak sistemlerinin ve komponentlerinin task süresinin tahmin edilmesi gerçekleştirilmiştir. Bu sayede bir uçağın ön tasarım sürecinde bakımları modelleyebilmek için literatüre yeni bir metot eklenmiştir.
\end{abstract}

Aircraft maintenance Neural networks Artificial Intelligence

\section{Development Of A New Method For Aircraft Maintainability Allocation}

\begin{abstract}
One of the most important topics in aircraft design is to define aircraft maintainability allocation which is a process to identify the allowable maximum task time for each aircraft component or system. Traditional methods are mostly experimental and out of design office's control. In this study, an improved method has been developed to create an alternative method for experimental ones. For this purpose, as a first step an existing methodology developed for maintenance allocation has been improved by using a different technic. Improved method shows that newly established correlation between aircraft systems and task times has very high coefficient of determination compare to the existing method. At the second phase of the study several quantitative analysis have been performed by examining more than 1000 maintenance tasks which are accepted as standard maintenance actions by aviation industry, coming from Maintenance Steering Group methodology and six weight factors have been established for the new method. By using feed forward artificial neural networks for newly identified weight factors, maintenance task allocations has been established. Results shows that newly proposed method can be applicable for any maintenance process during early design stage.
\end{abstract}

\section{GİRIŞ (INTRODUCTION)}

Bir ürünün dizaynı aşamasında, ürünün özelliklerine ve tasarımcının/firmanın tecrübesine göre farklı dizayn metodolojileri kullanılabilir. Bunlardan bazıları, imalat için dizayn (Design for Manufacturing DfM), montaj için dizayn (Design for Assembly - DfA), kalite için dizayn (Design for Quality - DfQ), güvenilirlik için dizayn (Design for Reliability - DfR), demontaj için dizayn (Design for Disassembly $\mathrm{DfD}$ ), herhangi bir şey için dizayn (Design for X - DfX), bakım yapılabilirlik için dizayn (Design for Maintainability - DfMa) olarak sayılabilir. Bu çalışmanın konusu olan, bakım yapılabilirlik açısından 
dizayn hususunda literatürde farklı çalışmaları görmek mümkündür. Desai[1], bakım açısından dizaynı ele aldığı çalışmasında literatür taraması yaparak temel konseptleri/kavramları ortaya koymuştur. Wahab[2], elektrikli kahve makinesi örneğinden yola çıkarak modüler dizayn ve bakım kolaylığı açısından bir dizayn metodolojisi önermiştir.

Coulibaly[3], semantik modelleme yöntemini kullanarak, dizaynın bakım ve emniyet açısından nasıl olması gerektiğine dair bir çözüm geliştirmiştir. Slavia[4] mikro motor, Zhong [5] ise sivil uçakların iniş takımları özelinde, fuzy logic kullanarak bakım yapılabilirlik modelleri geliştirmişılerdir. Chen[6], mekanik sistemlerin bakım yapılabilirliğini modellemek için vektör projeksiyon metodu ismini verdiği bir yöntem geliştirmiştir.

Chipchak[7], bakım tahsisine yönelik çalışması için pratik bir yöntem geliştirerek, Jenerik Modül Tipleri (Kj1), Hata Ayıklama Teknikleri(Kj2) ve Tasarım Karakteristiğindeki Farklar (Kj3) olmak üzere 3 farklı ağırlık faktörü belirlemiştir.

Tablo 1. Kj1 Ă̆ırlık Faktörü - Modüller [7]

\begin{tabular}{|c|c|c|}
\hline No & Modül & Puan \\
\hline 1 & Işılar & 1 \\
\hline 2 & Dijital & 1 \\
\hline 3 & Düşük seviye analog & 1,5 \\
\hline 4 & Yüksek seviye analog & 1,5 \\
\hline 5 & Dijital bilgisayarlar & 2 \\
\hline 6 & Güç kaynakları & 2 \\
\hline 7 & Elekromekanik ekipmanlar & 3 \\
\hline 8 & Yüksek güç/yüksek frekanslı komponentler & 4 \\
\hline 9 & Bağlantı Sistemleri & 4 \\
\hline 10 & Havalandırma & 4 \\
\hline 11 & Sivı soğutma sistemleri & 4 \\
\hline 12 & Mekanik yapıllar & 6 \\
\hline 13 & Dönen mekanizmalar/motorlar & 10 \\
\hline
\end{tabular}

Tablo 2. Kj2 Ağırlık Faktörü-Hata Ayıklama Teknikleri [7]

\begin{tabular}{|c|c|}
\hline Hata Ayıklama Tekniği & $\mathbf{K j 2}$ \\
\hline Otomatik & 0 \\
\hline Yar1-otomatik & 2 \\
\hline Manuel & 4 \\
\hline
\end{tabular}

Tablo 3. Kj3 Ă̆ırlık Faktörü - Modüler Dizayn Karakteristiği [7]

\begin{tabular}{|c|c|c|c|}
\hline M Dizayn Karakteristiği & Kj3 & \multicolumn{2}{|c|}{ Karakteristikler } \\
\hline Erişim/Uygulama & 0 & $\begin{array}{c}\text { Eoğrudş̧ erişim } \\
\text { kolaylığ }\end{array}$ & $\begin{array}{c}\text { Tek-adamulama kaldırma } \\
\text { ve taşıma }\end{array}$ \\
\hline Basit & 2 & $\begin{array}{c}\text { Birden fazla kapağı } \\
\text { açma/sistemi sökme }\end{array}$ & $\begin{array}{c}\text { 2 adamla kaldırma, zor } \\
\text { taşıma }\end{array}$ \\
\hline Zor & 4 & $\begin{array}{c}\text { Erişmek için ciddi efor } \\
\text { gereksinimi }\end{array}$ & $\begin{array}{c}\text { Makine yardımıyla } \\
\text { kaldırma ve taşıma }\end{array}$ \\
\hline Çok Zor & & & \\
\hline
\end{tabular}

Wan Husain [8], Chipchak'in ortaya koyduğu ağırlık faktörlerini referans alarak, Kj1'de verilen modüllerdeki puan değerleriyle, bu komponentlerin bakım süreleri arasındaki korelasyonu araştırmıştır. $\mathrm{Bu}$ amaçla MIL-HDBK-472 Prosedür III'u [9] temel almış ve bu modüllere uygulama süresi atayarak[10], bu sürelerle Chipchak'in atadığı puan değerleri arasındaki korelasyonu incelemiştir. 
Tablo 4. Kj1 Modül, Puan Ve Uygulama Zamanlarl [8]

\begin{tabular}{|c|c|c|c|c|}
\hline No & Modül & Dakika & Saat & Puan \\
\hline 1 & Işılar & 8,86 & 0,15 & 1 \\
\hline 2 & Dijital & 31,89 & 0,53 & 1 \\
\hline 3 & Düşük seviye analog & 31,89 & 0,53 & 1,5 \\
\hline 4 & Yüksek seviye analog & 31,89 & 0,53 & 1,5 \\
\hline 5 & Dijital bilgisayarlar & 22,66 & 0,38 & 2 \\
\hline 6 & Güç kaynakları & 20,18 & 0,34 & 2 \\
\hline 7 & Elekromekanik ekipmanlar & 64,45 & 1,07 & 3 \\
\hline 8 & Yüksek güç/yüksek frekanslı komponentler & 48,64 & 0,81 & 4 \\
\hline 9 & Bağlantı Sistemleri & 40,61 & 0,68 & 4 \\
\hline 10 & Havalandırma & 60,41 & 1,01 & 4 \\
\hline 11 & Siv1 soğutma sistemleri & 67,82 & 1,13 & 4 \\
\hline 12 & Mekanik yapılar & 79,20 & 1,32 & 6 \\
\hline 13 & Dönen mekanizmalar/motorlar & 368,84 & 6,15 & 10 \\
\hline
\end{tabular}

$\mathrm{Bu}$ ilişkinin varlığını doğruladıktan sonra (Şekil 1), trend analizleri yaparak uygulama süresinden puan değerini verecek en uygun formülü bulmayı hedeflemiş (Şekil 2) ve nihayetinde de R2 değeri en yüksek olan formülü(Tablo 5), yeni modüller ve bunlara karşılık gelen zamanları bulmak için kullanmıştır.

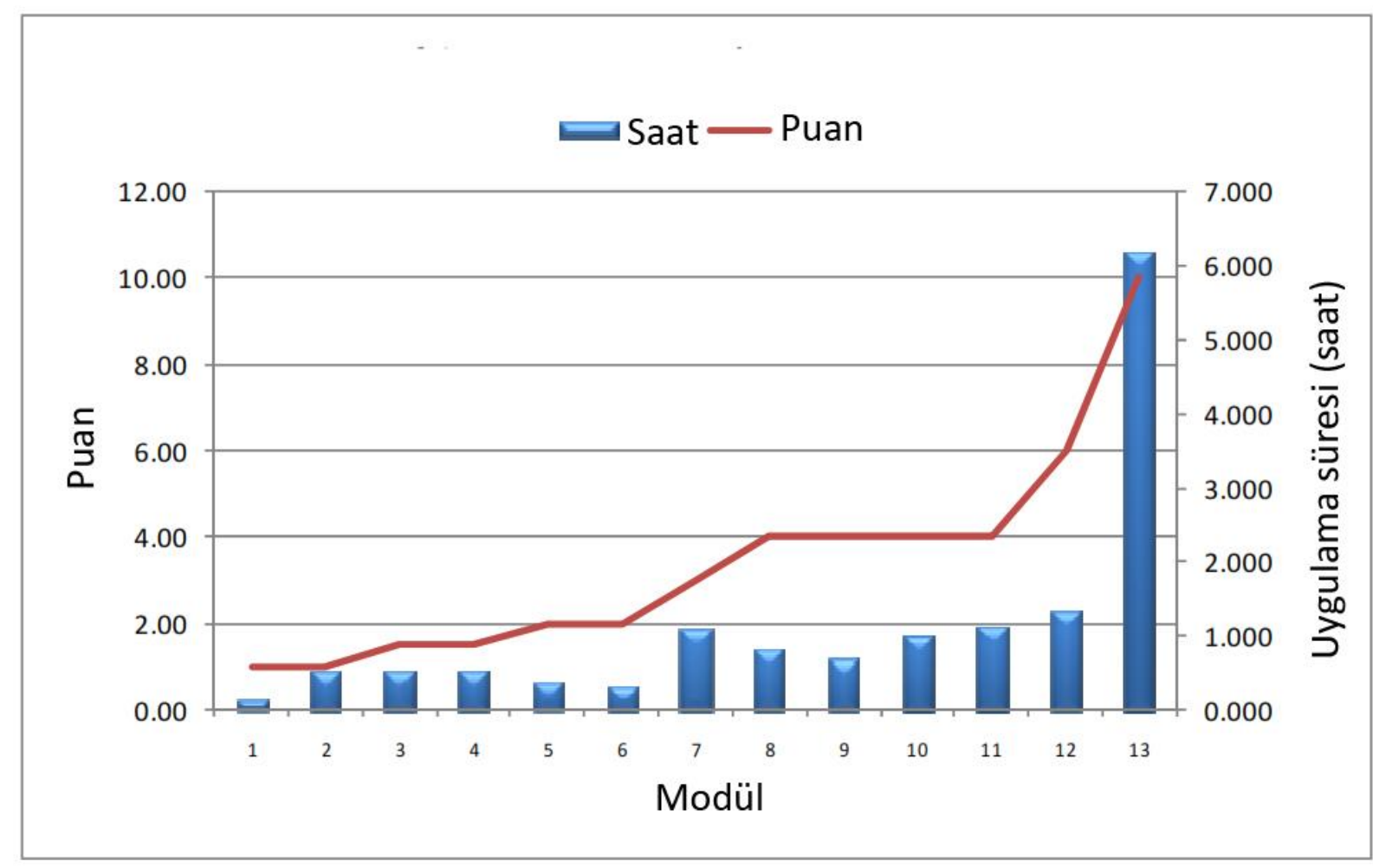

Şekil 1. Puan ve uygulama zamanları arasındaki ilişki [8] 

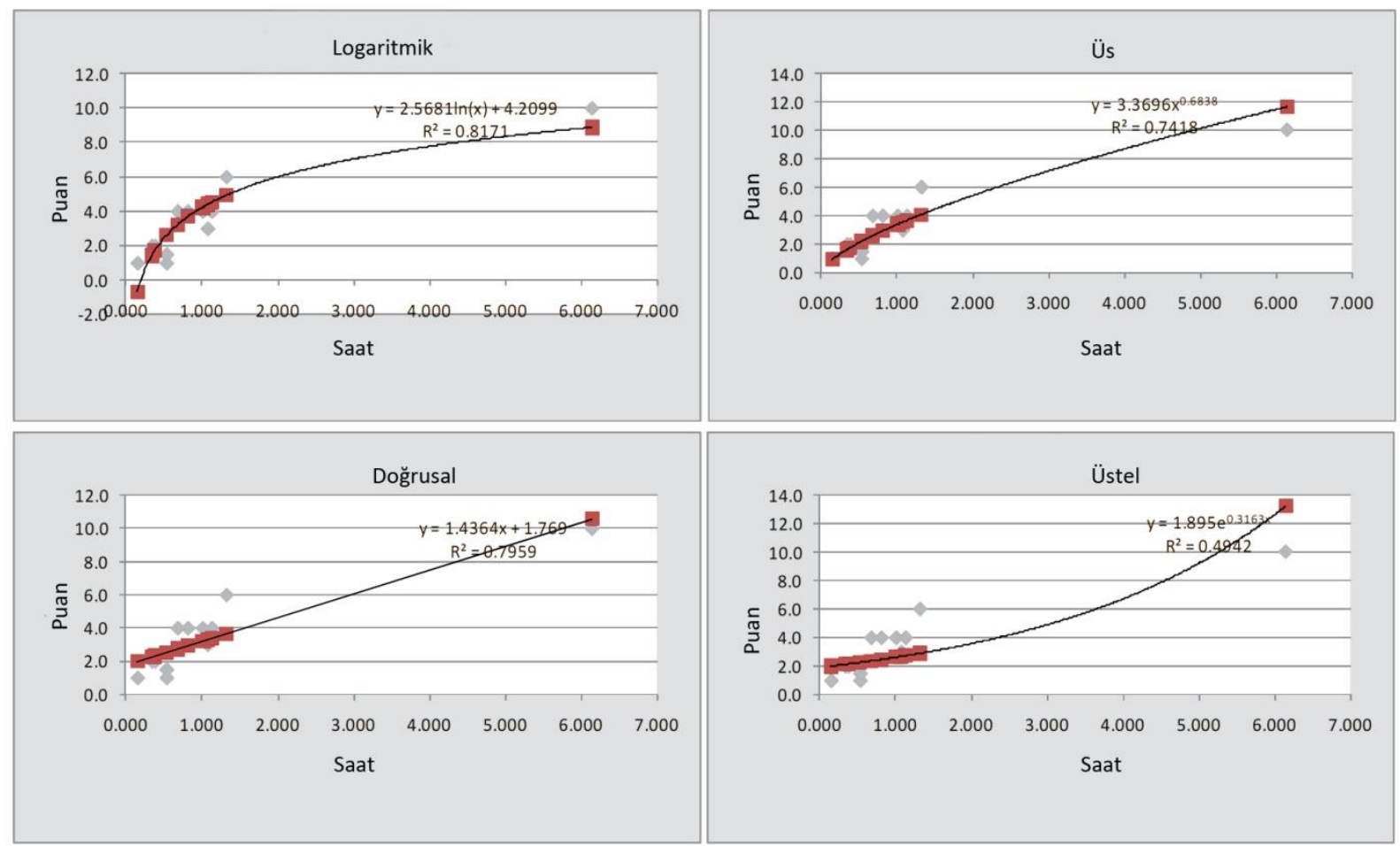

Şekil 2 : Trend analizleri [8]

Tablo 5. R2 Değerleri [8]

\begin{tabular}{|c|c|c|}
\hline Ĕ̆im Çizgisi & Formül & $\mathbf{R}^{\mathbf{2}}$ \\
\hline Logaritmik & $\mathrm{y}=2,5681 \ln (\mathrm{x})+4,2099$ & 0,8171 \\
\hline Doğrusal & $\mathrm{y}=1,4364 \mathrm{x}+1,769$ & 0,7959 \\
\hline Üs & $\mathrm{y}=3,3696 \mathrm{x}^{0,6838}$ & 0,7418 \\
\hline Üstel & $\mathrm{y}=1,895 \mathrm{e}^{0,3163 \mathrm{x}}$ & 0,4942 \\
\hline
\end{tabular}

\section{YAPAY SINIIR AĞLARI (YSA) TABANLI GELIŞTİIILMIŞ METOT (IMPROVED METHOD BASED ON ARTIFICIAL NEURAL NETWORKS)}

Bu çalışmada ise, Chipchak'in Kj1'de belirlediği modüller ve bunlara karşı gelen puan değerleri ile Wan Husain'in MIL-HDBK-472 Prosedür III'e göre atadığı uygulama zamanları referans alınmış, ancak puan değerleriyle uygulama zamanı arasındaki korelasyonu belirlemek için Wan Husain'den farklı olarak trend analizi değil yapay sinir ağları kullanılmıştır. Elde edilen korelasyon yeni modüller eklemek için kullanılmış, devamında ise bu modüller kullanılarak uçak bakım tasklarının uygulama sürelerini tahmin etmek için yine yapay sinir ağları ile bir yöntem geliştirilmiştir.

Chipchak'in önerdiği modüllerle bakım süreleri arasındaki korelasyonu araştırmak için öncelikle mevcut verilerin normalizasyonu yapılmıştır. Bu amaçla Log-sig, Tan-sig ve Pure-lin transfer fonksiyonları incelenmiş(Şekil 3), ancak analizde pozitif değerlerin kullanılması gerektiğinden Log-sig fonksiyonu seçilerek normalizasyon gerçekleştirilmiştir (Tablo 6). 


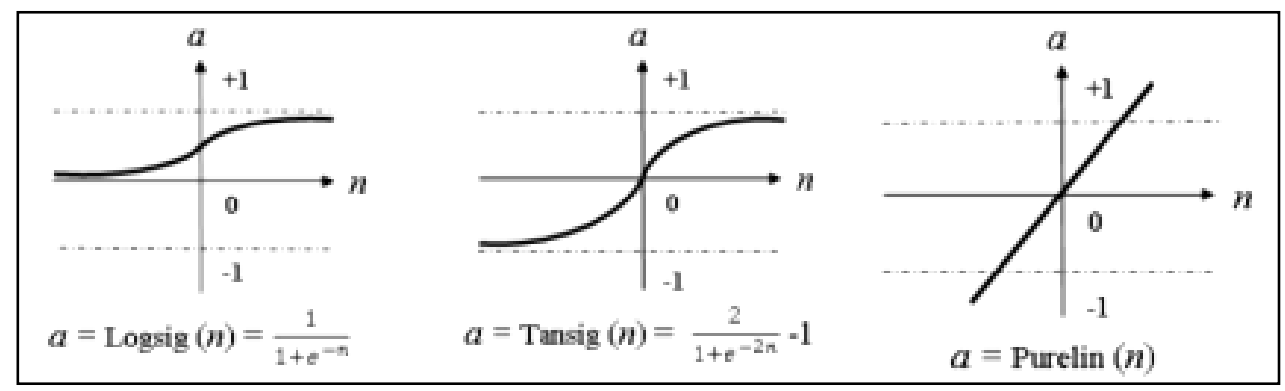

Şekil 3. Normalizasyon fonksiyonları

Tablo 6 : Puan ve uygulama zamanı verilerinin normalleştirilmesi

\begin{tabular}{|c|c|c|c|}
\hline \multicolumn{2}{|c|}{ Gerçek Veriler } & \multicolumn{2}{|c|}{ Normalleştirilmiş Veriler } \\
\hline 1 & 0.15 & 0.1 & 0.1 \\
\hline 1 & 0.53 & 0.1 & 0.35982906 \\
\hline 1.5 & 0.53 & 0.18 & 0.35982906 \\
\hline 1.5 & 0.53 & 0.18 & 0.35982906 \\
\hline 2 & 0.38 & 0.26 & 0.257264957 \\
\hline 2 & 0.34 & 0.26 & 0.22991453 \\
\hline 3 & 1.07 & 0.42 & 0.729059829 \\
\hline 4 & 0.81 & 0.58 & 0.551282051 \\
\hline 4 & 0.68 & 0.58 & 0.462393162 \\
\hline 4 & 1.01 & 0.58 & 0.688034188 \\
\hline 4 & 1.13 & 0.58 & 0.77008547 \\
\hline 6 & 1.32 & 0.9 & 0.9 \\
\hline
\end{tabular}

Normalize edilen değerlerden bir grup, test verisi olarak ayrılıp yapay sinir ağlarında eğitim amacıyla kullanılmıştır. Test verilerini eğitmek için 2 katmanlı, 8 nörondan oluşan "ileri beslemeli ağ" seçilmiştir. Ağın bulduğu değerler ile gerçek test değerlerinin ne kadar yakın olduğunu görmek ve seçilen algoritmanın doğruluğunu gözlemlemek amacıyla Şekil 4'de verilen karşılaştırma yapılmış ve yeni bir fonksiyon elde edilmiştir. 


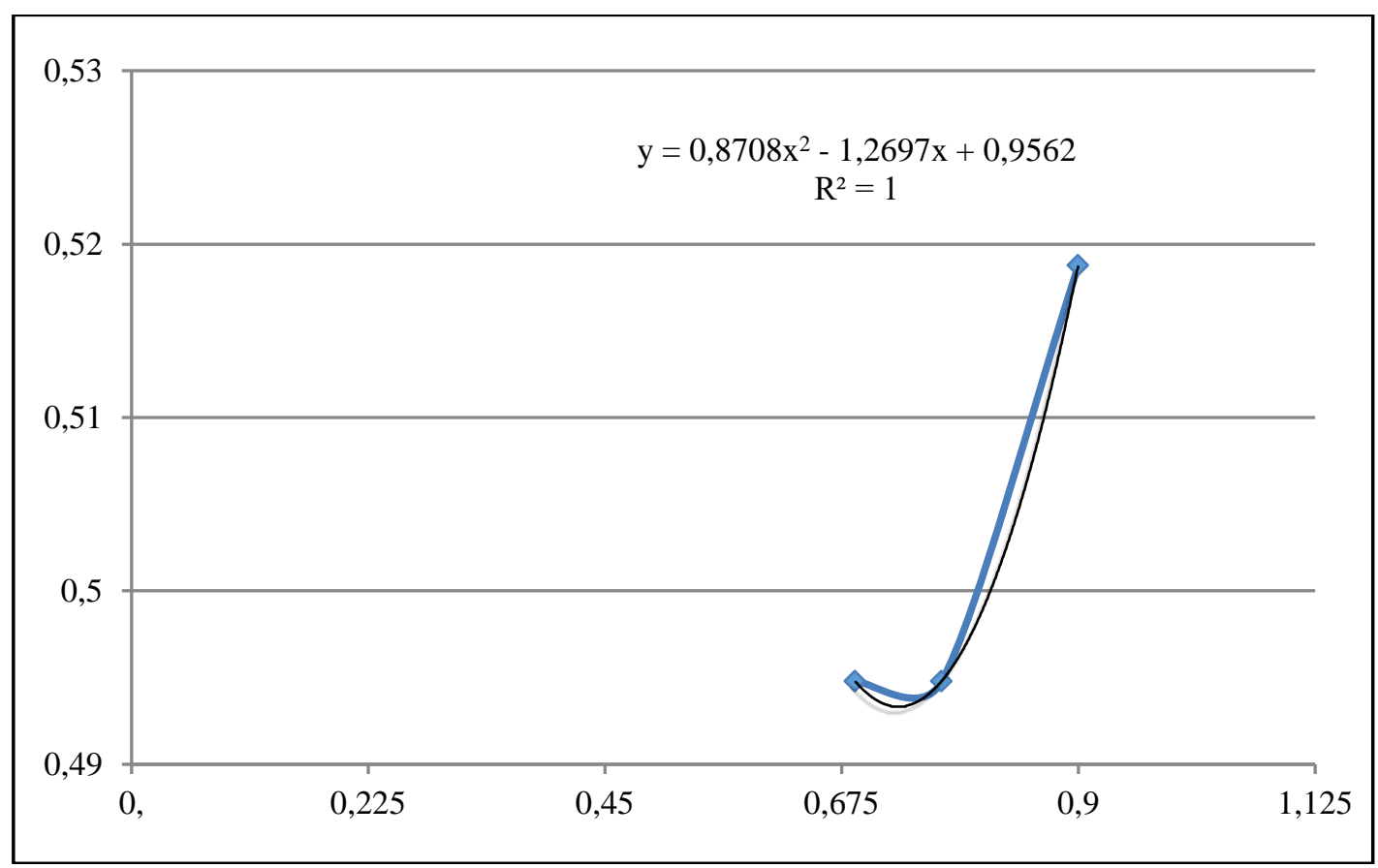

Şekil 4. YSA'nın eăitimi sonucu elde edilen değerle, gerçek verinin karşılaş̧ııılması

Yukarıdaki grafikten de görüleceği üzere $\mathrm{R}^{2}=1$ sonucu elde edilmiş, yani mükemmel bir sonuca ulaşılmıştır. Bu sonucu veren denklem ise

$$
y=0.8708 x^{2}-1.2698 x+0.9562
$$

ile belirlenmiştir. Hatırlanacağı üzere Wan Husain'in metodunda $R^{2}=0,8171$ olarak elde edilmişti.

Çalışmanın ikinci aşamasında, ilk bölümde $\mathrm{k}_{1}$ ağırlık katsayıları şeklinde tanımlanan modüllerle, bu modüllere uygulanan farklı bakım taskları arasındaki ilişki araştırılmıştır. Bu amaçla, Maintenance Steering Group olarak adlandırılan ve uçak imalatçıları, otoriteler ve kullanıcılardan oluşan komitenin belirlediği ve tüm dünyada standart olarak kullanılan temel tasklar dikkate alınmıştır. Genel gözle kontrol(General Visual Inspection - GVI), detaylı gözle kontrol(Detailed Visual Inspection - DVI), fonksiyonel kontrol(Functional Check - FUC), operasyonel kontrol(Operational check - OPC), sökme takma(Removal And Installation -RAI), yağlama (Lubrication - LUB) ve servisten (Service - SRV) oluşan bu tasklar, yapılan kantitatif çalışmayla 3 aşamaya ayrılmış, zorluk derecesi ve uygulama için teknisyende olması gereken yetki veya lisans seviyesine göre bir ağırlık katsayısı $\left(\mathrm{k}_{2}\right)$ belirlenmiştir. Ancak sökme takma (REM/INS) ve yağlama taskları(LUB), uygulandığı komponente göre değişik ağırlık katsayılarına sahip olması gerektiğinden kendi içinde 3 aşamalı olarak düşünülmüş ve yağlama için LUB1, LUB2, LUB3, sökme takma için RAI1, RAI2, RAI3 sinıflandırması yapılmıştır. Bu çalışma kapsamında bir hava yoluna ait Boeing 737-800 uçağının gerçek bakım verileri kullanılmış olup, filonun $\mathrm{C}$ bakımındaki değerleri esas alınmıştır. 
Tablo 7. Temel tasklar ve gruplandırma

\begin{tabular}{|c|c|c|}
\hline Kısaltma & Task İsmi & Grup \\
\hline SRV & Servis & \\
LUB & Yağlama & \\
RAI1 & Sökme\&Takma & 1 \\
SMP & Örnekleme & \\
DRN & Drenaj & \\
CLN & Temizlik & \\
\hline RST & Yenileme için söküm & \\
REP & Değiştirme & \\
LUB & Yağlama & \\
RAI2 & Sökme\&Takma & \\
DIS & Kal etme & \\
CGK & Kontol & \\
GVI & Genel gözle inceleme & \\
OPC & Operasyonel kontrol & \\
\hline ADJ & Ayarlama & \\
CPC & Korozyon kontrolü & \\
LUB3 & Yağlama & \\
RAI3 & Sökme\&Takma & \\
DVI & Detaylı gözle inceleme & \\
FUC & Fonksiyonel kontrol & \\
\hline
\end{tabular}

Tablo 8. k2 Ağırlık katsayısı için gruplama

\begin{tabular}{|ccccc|}
\hline \multicolumn{5}{c|}{ Yetkili Teknisyen } \\
\hline Grup(k2) & Kategori & Lisans & Tip & Task Eğitimi \\
\hline 1 & & & & $\sqrt{ }$ \\
\hline & & & & $\sqrt{ }$ \\
& B1/B2 & $\sqrt{ }$ & & \\
3 & & & $\sqrt{ }$ & \\
\hline & B1/B2 & $\sqrt{ }$ & $\sqrt{ }$ & \\
\hline
\end{tabular}


Diğer ağırlık katsayısı olan $\mathrm{k}_{3}$ ise taskı uygulayacak personel sayısı olarak değerlendirilmiştir. İlgili taskı sadece 1 personelin uygulaması durumunda $\mathrm{k}_{3}=1,2$ personelin uygulaması durumunda, benzer şekilde $\mathrm{k}_{3}=2$ değerini alacaktır.

Task1 uygulamak için herhangi bir ekipman, cihaz vs.'nin gerekmesi durumu da çalışmada dikkate alınmış ve gereksinim durumu $\mathrm{k}_{4}$ ağırlık katsayısı ile tanımlanmıştır. Ekipman ya da cihazın şart olduğu durumda $\mathrm{k}_{4}=1$, aksi halde $\mathrm{k}_{4}=0$ olarak tanımlanmıştır.

Özellikle iniş takımları ve flaplar gibi hidromekanik sistemlerle, güç sistemleri ve bazı yapısal sistemlere ait taskların uygulanabilmesi için bir takım ön gereksinimler mevcuttur. Mesela iniş takımlarının fonksiyonel kontrollerini yapabilmek için uçağın jack'e(özel bir aparata) alınması gerekir ki, bu da bakım süresini uzatan bir faktördür. Bu durumu dikkate alarak, bir taskın uygulanması için ön gereksinimi olup olmadığına dair durum çalışmaya katılmış ve $\mathrm{k}_{5}$ ile gösterilmiştir. Ön gereksinim olması durumunda $\mathrm{k}_{5}=1$, aksi durumda ise $\mathrm{k}_{5}=0$ olacaktır.

Çalışmanın nihai amacı olan $\mathrm{k}_{6}$ ise, o taskı uygulamak için gerekli olan adam/saati ifade etmektedir.

Tablo 9: A ̈̆ırlık katsayıları

\begin{tabular}{|cl|}
\multicolumn{2}{c|}{ Tablo 9:A ̈ı̆lık katsayıları } \\
\hline Katsayı & Açılaması \\
\hline $\mathbf{k}_{\mathbf{1}}$ & Uçak komponentleri/sistemleri \\
$\mathbf{k}_{\mathbf{2}}$ & Tasklar \\
$\mathbf{k}_{\mathbf{3}}$ & Kişi sayısı \\
$\mathbf{k}_{\mathbf{4}}$ & Ekipman gereksinimi \\
$\mathbf{k}_{\mathbf{5}}$ & Ön gereksinim \\
$\mathbf{k}_{\mathbf{6}}$ & Adam/Saat \\
\hline
\end{tabular}

Chipchak tarafından elde edilen ve Tablo 4 ile verilen modüllere, (1) eşitliği kullanılarak yeni modüller eklenmiş ve böylece uçağın ana komponentleri ya da sistemleri için k1 katsayıları belirlenmiştir. Bu komponent ya da sistemlere dair rastgele tasklar seçilmiş ve bu tasklarla ilgili kişi sayısı, ekipman gereksinimi, ön gereksinim ve A/S gibi değerler için bir havayolunun verileri kullanılmıştır (Tablo 10). 
Tablo 10: Komponent ve sistemler için ağırlık katsayılarının dă̆ lımı

\begin{tabular}{|c|c|c|c|c|c|c|c|}
\hline & k1 & Tasklar & k2 & k3 & k4 & k5 & k6 \\
\hline \multirow{5}{*}{ MOTOR } & 10 & GVI & 2 & 1 & 0 & 0 & 0,5 \\
\hline & 10 & OPC & 2 & 2 & 0 & 0 & 3,67 \\
\hline & 10 & REM & 3 & 5 & 1 & 1 & 20,25 \\
\hline & 10 & INS & 3 & 5 & 1 & 1 & 36,33 \\
\hline & 10 & SRV & 1 & 1 & 1 & 0 & 0,42 \\
\hline \multirow{5}{*}{$\begin{array}{l}\text { MLG (ANA İNİŞ } \\
\text { TAKIMI) }\end{array}$} & 8 & LUB & 1 & 2 & 1 & 0 & 1,5 \\
\hline & 8 & SRV & 3 & 2 & 1 & 0 & 1 \\
\hline & 8 & DVI & 2 & 1 & 1 & 0 & 0,58 \\
\hline & 8 & GVI & 2 & 1 & 0 & 0 & 0,42 \\
\hline & 8 & FUC & 3 & 5 & 1 & 1 & 6,75 \\
\hline \multirow{5}{*}{$\begin{array}{l}\text { NLG (BURUN İNIŞ } \\
\text { TAKIMI) }\end{array}$} & 8 & LUB & 1 & 2 & 1 & 0 & 1,17 \\
\hline & 8 & SRV & 3 & 2 & 1 & 0 & 2,42 \\
\hline & 8 & DVI & 3 & 1 & 1 & 0 & 0,33 \\
\hline & 8 & GVI & 2 & 1 & 0 & 0 & 0,42 \\
\hline & 8 & FUC & 3 & 5 & 1 & 1 & 6 \\
\hline \multirow{4}{*}{ KANATÇIK } & 8 & LUB & 1 & 2 & 1 & 0 & 0,58 \\
\hline & 8 & GVI & 2 & 1 & 0 & 0 & 0,42 \\
\hline & 8 & OPC & 3 & 3 & 1 & 0 & 0,67 \\
\hline & 8 & DVI & 2 & 1 & 0 & 0 & 0,25 \\
\hline \multirow{4}{*}{ STABILIZER } & 8 & LUB & 1 & 1 & 1 & 0 & 0,3 \\
\hline & 8 & FUC & 3 & 2 & 1 & 0 & 1,33 \\
\hline & 8 & DVI & 3 & 1 & 1 & 0 & 0,58 \\
\hline & 8 & OPC & 3 & 3 & 1 & 0 & 1,25 \\
\hline \multirow{4}{*}{ IŞIKLAR } & 1 & OPC & 2 & 1 & 0 & 0 & 0,25 \\
\hline & 1 & FUC & 3 & 1 & 0 & 0 & 0,42 \\
\hline & 1 & GVI & 1 & 1 & 0 & 0 & 0,67 \\
\hline & 1 & RAI3 & 3 & 1 & 0 & 0 & 2,17 \\
\hline \multirow{2}{*}{ PİOT } & 2 & FUC & 3 & 2 & 1 & 0 & 1,33 \\
\hline & 2 & DVI & 3 & 1 & 1 & 0 & 0,25 \\
\hline \multirow{2}{*}{ STATIKK PORTLAR } & 2 & $\overline{\text { FUC }}$ & 3 & 2 & 1 & $\overline{0}$ & 1,33 \\
\hline & 2 & DVI & 2 & 1 & 0 & 0 & 0,5 \\
\hline OKSİJEN & 2 & OPC & 3 & 2 & 1 & 0 & 3 \\
\hline SISTTEMLERİ & 2 & GVI & 3 & 1 & 0 & 0 & 3 \\
\hline
\end{tabular}

Elde edilen değerlerin \%80'i eğitim için, \%20'si de test için ayrılmış ve analiz için yine yapay sinir ağları kullanılmıştır. İlk bölümde olduğu gibi önce değerler normalize edilmiş, sonra da ileri beslemeli bir ağ kullanılarak \%80'lik veri seti eğitime tabi tutulmuştur. Sonuçların ne kadar gerçekçi olduğunu görmek için ayrılan \%20'lik test seti ile sonuçlar karşılaştırıldığında $\mathrm{R}^{2}=0,8763$ olarak elde edilmiştir ki, bu da yaklaşımın oldukça doğru olduğunu ifade etmektedir. Bu sonucu veren formül ise

$$
y=22,42 x^{2}-5,2918 x+0,4389
$$

olarak elde edilmiştir (Şekil 5). 


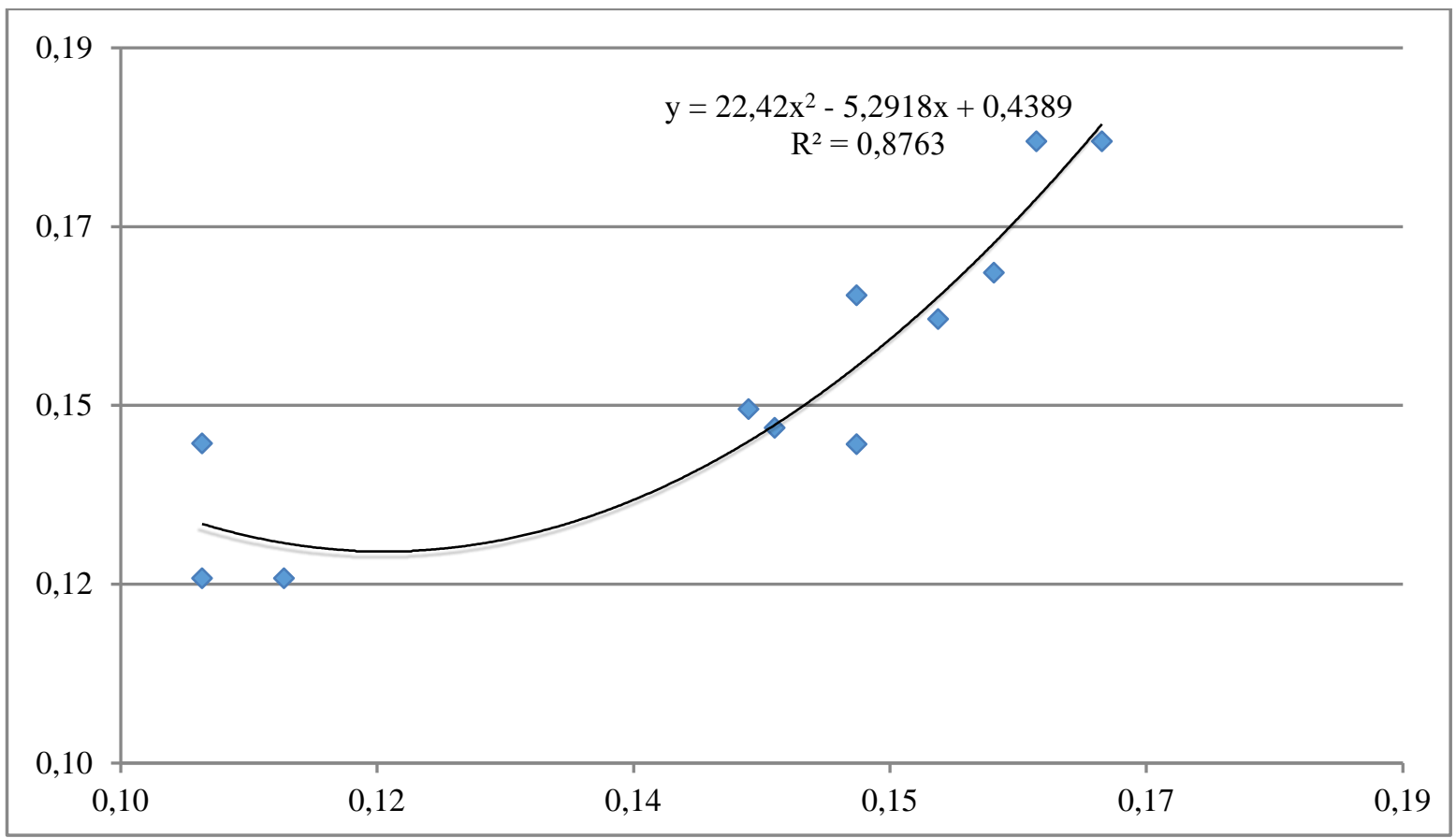

Şekil 5 : YSA'nın eğitimi sonucu elde edilen değerle, gerçek verinin karşılaştırılması

\section{SONUÇ (CONCLUSION)}

Tasarımın bakım kolaylı̆̆ı üzerine temellendirildiği metodoloji için önceki yıllarda farklı yöntemler önerilmiştir. Ancak havacılık alanında bu konu özelindeki çalışmalar, havacılık firmalarının verilerini pek paylaşmama yönündeki yaklaşımları nedeniyle, genellikle tecrübi ya da istatistiki çalışmalar üzerine kurgulanmıştır. Temeli MIL-HDBK-472'a [9] dayanan bu çalışmalar, sürecin farklı yöntemlerle hızlandırılması üzerine şekillendirilmiş olup, bu anlamda yapılan son çalışmaların birinde[8], önerilen sistemin doğruluk oranı $\mathrm{R}^{2}=0,8171$ olarak elde edilmiştir. Bu makalede geçen çalışmada ise, yapay sinir ağları ile yeni bir yöntem geliştirilerek uçak tasarımcısına, tasarım aşamasında hızlı ve efektif bir yöntem sunulması hedeflenmiştir. Çalışmanın sonunda uçağın motor, yardımcı güç ünitesi, iniş takımları gibi ana komponentlerine uygulanması gereken temel taskların uygulama süresi, $\mathrm{R}^{2}=0,8763$ değeriyle doğru tahmin edilmiştir. Bu sayede, bir hava aracının ön tasarım safhasındaki süreçlerden biri olan bakım modellemesi için literatüre yeni bir yöntem eklenmiştir.

$\mathrm{Bu}$ çalışma kapsamında geliştirilen metot, sadece uçak sistemleri için uygulanmış olup, kompleks yapılarından dolayı uçak yapısal sistemleri dikkate alınmamıştır. Bununla birlikte, yapısal sistemler üzerinde yapılacak benzeri bir çalışma için bu metot kullanılabilir, ancak gerçek verilerin kullanılabilmesi yüksek güvenilirlik oranı elde etme açısından önemlidir.

\section{KAYNAKLAR (REFERENCES)}

[1] Desai, A. ve Mital, A., "Design For Maintenance: Basic Concepts And Review Of Literature", International Journal of Product Development, Vol. 3, No. 1, 77-121, 2006

[2] Wahab, D. A., Ching, K. E., Boay, T. A., Ramli, R. ve Hussain, A., "Product Redesign For Ease Of Maintenance: A Case Study", International Journal of Mechanical and Materials Engineering, vol. 3, no. 2, 153-159, 2008

[3] Coulibaly, A., Houssin, R. and Mutel, B., "Maintainability And Safety Indicators At Design Stage For Mechanical Products", Computers in Industry, vol.59, no. 5, 438-449., 2008 
[4] Slavila, C. A., Decreuse, C. and Ferney, M., "Fuzzy Approach For Maintainability Evaluation In The Design Process", Concurrent Engineering Research and Applications, vol. 13, no. 4, 291-300., 2005

[5] Zhong, L. and Youchao, S., "Research On Maintainability Evaluation Model Based On Fuzzy Theory", Chin J Aeronaut, vol. 20, no. 5, 402-407, 2007

[6]. Chen, L. and Cai, J., "Using Vector Projection Method to evaluate maintainability of mechanical system in design review", Reliability Engineering \& System Safety, vol. 81, no. 2, 147-154., 2003

[7] Chipchak, J.S., "A Practical Method Of Maintainability Allocation", Aerospace and Electronic Systems, IEEE Transactions, Volume AES-7, Issue:4, 1971

[8] Wan H., Wan M.S., "Maintainability Prediction for Aircraft Mechanical Components Utilizing Aircraft Feedback Information”, Applied Mechanics and Materials, vol. 225, 528-533, 2012

[9] MIL-HDBK-472, Maintainability Prediction, MIL-HDBK-472, Department of Defense, Washington, DC., 1966

[10] DOD-HDBK-791, "Maintainability Design Techniques”, DOD-HDBK-791, Department of Defense, USA., 1988 